\title{
A LITERATURA MARGINAL NA INTERNET: O FENÔMENO FANFICTION COMO INSTRUMENTO DE DISSEMINAÇÃ̃O E DIVULGAÇÃO DAS/NAS MARGENS
}

\author{
André de Jesus Neves (Pós-Crítica/UNEB)
}

\begin{abstract}
RESUMO: A literatura, seu foco de discussão e campo de atuação têm sido deslocados e têm permitido novas aberturas nas últimas décadas e, com o surgimento da internet, novas formas de produções literárias, ou ciberliteraturas, têm surgido e ampliado esse campo. O presente texto constitui-se de uma proposta de análise e compreensão do fenômeno fanfiction, como produção literária marginal nos espaços virtuais que coloca em xeque e amplia a discussão de autoria dentro de uma abordagem que supera uma série de conceitos estruturadores do pensamento sobe a literatura; analisará, também, o deslocamento do eixo de hegemonia dentro do processo de produção literária. Por fanfiction aqui, compreende-se o hobby literário, cujo objetivo é (re)escrever histórias baseadas em universos ficcionais - personagens, cenários e acontecimentos - criados por terceiros (fãs) no ciberespaço. Na maioria dos casos, esses escritores de fanfic ou ficwriters têm como principal inspiração as histórias lançadas pelo mercado da indústria cultural, como livros, filmes, desenhos animados, quadrinhos e seriados de TV. Diante disso, trata-se de uma discussão à luz dos estudos literários e dos Estudos Culturais, buscando compreender a lógica dessa "sub-cultura", como forma de disseminação de outras obras já postas em evidência pelas academias e mercado cultural.
\end{abstract}

PALAVRAS-CHAVE: literatura marginal, fanfiction, cultura participatória, ciberliteratura.

\begin{abstract}
The literature, its discussion focus and field of performance have been moved and it has been allowed new openings in the last decades and, with the appearance of the internet, new forms of literary productions, or cyberliterature, have appeared and enlarged that field. The present text is constituted of an analysis proposal and understanding of the "phenomenon fanfiction", as marginal literary production in the virtual spaces wnicle it puts in check and it enlarges the authorship discussion of an approach that overcomes a series of concepts of estructures creator of the literature, thoughot will analyze, also, the displacement of the hegemony axis inside of the process of literary production. For "fanfiction", here, we understand the hobby literary writing, whose objective is to write and to redraft stories based on universes fictional - characters, sceneries and events - created by third (fans) in the cyberspace. In most of the cases, those fanfic writers or ficwriters have as main inspiration the histories thrown by the market of the cultural industry, as books, films, cartoons, frames and serial of TV. Before that, it is treated from a discussion to the light of the literary studies and of the Cultural Studies, besides looking for to understanding the logic of that " sub-culture ", as a form of spread of other works already in evidence for the academies and cultural market.
\end{abstract}

KEYWORDS: Marginal literature, fanfiction, participatory culture, cyberliterature.

\section{INTRODUÇÃO}

Com o fenômeno da cultura de massa, altamente expressivo na sociedade do capitalismo tardio e notadamente "consumível", como filmes, seriados de TV, livros, 
etc, surge a "cultura de fã", esse que não apenas se satisfará em buscar novos produtos culturais derivados como vai, ele mesmo, sozinho ou em conjunto com outros fãs, criar novos produtos culturais derivados. Surge então, nesse contexto, dentro de um novo cenário, o do ciberespaço, ou espaço virtual, o alargamento dessa cultura, permitindo o nascimento de uma geração de fãs produtores/reprodutores que deixam de ser meros consumidores da cultura de massa e passam a ter um papel importante na relação com a cultura pop que "consomem", de meros consumidores passam a ser (re)produtores inconformados com a "originalidade" imposta pelo autor. Neste artigo, pretendo analisar a cultura de fãs e seu papel participatório na (re)produção de obras, reconfiguração de personagens e cenários que, nos últimos anos, ganhou uma grande expansão no ciberespaço, mais especificamente com a categoria fanfiction. O presente artigo objetiva, ainda, em primeira instância, fazer uma abordagem ao fenômeno fanfiction, como cultura participatória no contexto do ciberespaço e, em segunda, estabelecer uma breve comparação entre estas e outras formas de criação ou divulgação da literatura na Internet, analisando seu papel político dentro de um contexto de marginalidade, de arte subalterna, e, como ele "interage" com alguns dos "princípios básicos" da Teoria da Literatura e Crítica Literária, tais como literariedade ou autoria.

Derivado do inglês, participatory culture, o termo cultura participatória é utilizado para designar uma cultura na qual fãs se apropriam de produtos culturais, do conceito de seus personagens e os reproduzem modificando sua história e criando produtos derivados.

Ao analisar a história da literatura, observa-se uma pretensão ao universal, contudo, percebe-se que a partir dos anos 70 houve uma notável abertura para outras formas do fazer literário e a descentralização do foco exclusivamente literário que permitiu que outros focos, antes periféricos, encontrassem lugar na discussão literária, daí então a consagração dos cânones entrou em discussão. Novas questões passaram a ser levantadas, a partir de então, tais como: $a$. Quem deve determinar o que é literatura? $b$. Para quem é literatura e para quem não é literatura? c. Quais fatores determinam que um texto apresenta literariedade e outro não?

O sentido de literatura, a ser discutido aqui, aponta para uma cultura como símbolo de resistência e produção de novos significados políticos no contexto da globalização, aponta também para uma extrapolação das supostas respostas aos 
questionamentos acima, visto que a literatura no contexto atual requer novas propostas de construção e divulgação. Neste sentido, a noção de cultura e, consequentemente, de literatura, é forçada a repensar seus parâmetros e até mesmo sua função social.

É notável que as características e expressões artísticas marginais, periféricas e/ou subalternas, principalmente no que se refere à literatura, têm surpreendido, visto que suas manifestações têm se voltado para temas esquecidos pelas "literaturas canônicas" com uma atenção significativa aos temas da miséria, da fome, das desigualdades sociais e, ultimamente, da violência urbana; tem-se percebido, nesse contexto temático, maior engajamento político e compromisso social do intelectual, neste caso, do escritor.

Contudo, o que passo a descrever e a analisar aqui transpõe esses espaços, pois a abertura no foco das discussões no campo da literatura tem ampliado significativamente os meios de produção e disseminação da mesma e perpassa as questões sociais e, sobretudo, culturais. Nota-se, nesse sentido, que, com o surgimento da internet, a literatura mais uma vez é posta em xeque, quanto ao seu lugar, autoria e valor. Que literatura se inventa nesse contexto volátil, fluido, hipertextual, dinâmico e desterriorializado? Qual é a importância do autor/escritor no contexto da cibercultura? Que novas criações estão surgindo nesse novo espaço? E de que forma a cultura de fã, a cultura participatória, contribui para essas transformações literárias nesse novo contexto?

\section{A CULTURA DE FÃ E A LITERATURA NO CIBERESPAÇO}

Antes de descrever o fenômeno fanfiction pretende-se analisar a cultura participatória no ciberespaço como fruto do desenvolvimento tecnológico aliado a diversas questões culturais. Essa interatividade crescente nos grandes meios tem levado muitos teóricos a repensar seus conceitos sobre o suposto caráter manipulativo e alienante da comunicação de massa e da indústria cultural. Martin-Barbero defende a existência de um deslocamento do eixo de hegemonia dentro do processo comunicativo. Para o autor, compreender a comunicação não se resume apenas a investigar astúcias do dominador, mas também aquilo que no, dominado, trabalha a favor do dominador, isto 
é, a cumplicidade de sua parte, e a sedução que se produz entre ambos (MARTINBARBERO, 2006).

Tomo como dominador aqui, um conjunto de elementos "estruturadores da ordem”, não só estéticos como também sociais e culturais; construções ideológicas de poder e dominação de cultura, assim como os produtos elaborados e impostos pela cultura chamada "dominante".

O deslocamento do eixo hegemônico que ocorre da cultura dominante para outras denominadas subalternas não é providencial, mas consequência de resistências no interior de uma arena de tensões entre dominador e dominado, entre as normas e suas rupturas, entre a ideologia e a contra-ideologia, senso e contra-senso, entre o fechamento e a multiplicidade, entre o centro e a marginalidade.

A relação que se dá entre/nessas dicotomias, apesar da oposição, é também uma relação dialógica e de completude, pois não se excluem, completam-se. Uma sobrevive em consequência da outra.

$\mathrm{Na}$ contemporaneidade, com a explosão da cultura de mercado, observa-se um crescente consumismo cultural, ideologicamente programado para as massas, contudo essa "cultura pop" transforma-se em matéria-prima para seus usuários/fãs. Eles deixam de ser meramente consumidores e passam a ser co-produtores e/ou (re)produtores dessa cultura, exercendo um papel importante tanto no consumo quanto na disseminação cultural, não apenas como meros consumidores, mas também como intérpretes da cultura que lhes fora imposta, e como transformadores e agentes culturais. A esse respeito Silviano Santiago ${ }^{1}$ diz que houve uma democratização cultural, enquanto a arte (hegemônica) entrou em declínio.

Nesse sentido, nota-se que, com o surgimento da web, houve uma grande expansão da cultura de fã, pelo fato de a internet propiciar maior acesso, tanto às obras quanto aos produtos derivados dessas e sua divulgação. O ciberespaço gera, nesse contexto cibercultural, um ambiente de fluxo de produção e trocas, no qual a produção literária encontra espaço para novos escritores de ficção, os ficwriters. Dessa forma, a literatura no espaço virtual torna-se um terreno fértil de diálogo entre culturas, cuja diluição e hibridação são inevitáveis. Assim como seus produtos culturais também se diluem, hibridam-se, perdem poder hegemônico e autonomia autoral, como ocorre com 
os cânones em relação à cultura de fã; em consequência disso a cultura torna-se participatória e menos hegemônica e centralizada, torna-se democrática no sentido já exposto por Silviano Santiago.

Toma-se aqui, como principal elemento para discussão, dentre os diversos tipos de cultura participatória, a fanfiction, cuja explosão no ciberespaço, nos últimos anos, tem alcançado notoriedade. Fanfic, fenômeno aqui analisado, é a abreviação do termo em inglês fan fiction, ou seja, "ficção criada por fãs", no ciberespaço (blogs e comunidades virtuais), de forma individual ou coletiva. Trata-se de contos ou romances (re)escritos por terceiros, que não fazem parte do enredo oficial do livro, filme ou história em quadrinhos a que fazem referência. Uma das características que une essas expressões culturais e outras relacionadas à cultura participatória é o desejo de se expandir universos ficcionais sem o intuito de lucro.

Essa filosofia de criação aberta e desprezo pelo copyright encontrou terreno fértil para expansão no ciberespaço, ou espaço virtual.

Segundo Lima (2009 on line), “a essência do virtual é a representação da realidade, simulando um tempo e um espaço, ou melhor (sic), uma temporalidade e uma espacialidade especiais, em uma dimensão espectral. Não se trata de uma dimensão paralela do real, pois o real e o virtual se interligam, em diferentes pontos". Ao tratar da relação entre o literário e o virtual, ele afirma que "o literário - como o virtual - é também representação, embora seja muito mais que isto, pois possui um certo grau de autonomia em relação ao real”.

Como representação, é notável, no contexto da globalização e da cultura midiática, sobretudo da internet, que vivemos também a cultura do simulacro, reportando a Jean Braudillard quando afirma que "livre do real, você pode fazer algo mais real que o real: o hiper-real"; é possível dizer que a liberdade no ciberespaço e na literatura conduz à fuga do real que permite, muitas vezes, a sua recriação como a busca de "uma realidade" desejável, possível, como a eterna busca do Graal.

Nesse sentido, no que se refere à cultura participatória, observa-se que o mundo produzido não é o mundo desejável. Portanto, a ação da (re)criação de uma cultura derivada da cultura que o individuo consome, mas não o satisfaz, torna-se necessária, daí o nascimento de um novo simulacro, uma simulação contínua, como uma busca que 
não se concretiza, pois "ao contrário da utopia, a simulação começa a partir do princípio da equivalência, da negação radical do signo como valor, parte do sinal de reversão e supressão de qualquer referência" (Baudrillard,1978, p. 13, tradução nossa) ${ }^{1}$.

Para uma compreensão mais acentuada da cultura de fã, fanfiction, na internet, num contexto de produção e disseminação cultural da arte subalterna nas margens, no ciberespaço, é necessário entender como ele funciona e/ou opera.

As fan fictions, mais conhecidas pelo acrônimo "fanfic", ampliaram o conceito de apropriação das criações alheias pelos fãs. Fan fiction pode ser traduzida para português como "ficção de fã". Sob essa "nomenclatura" reúnem-se essencialmente histórias que fãs escrevem sobre personagens ou universos ficcionais de que gostam, seja de literatura, cinema, quadrinhos ou qualquer outra mídia. Os escritores de fanfics são popularmente chamados de fanfiqueiros ou ficwriters.

Entre os autores e leitores de fanfiction, existem várias pessoas que começaram o seu contato com os textos em fanzines (Fanzine é uma abreviação de fanatic magazine, mais propriamente da aglutinação da última sílaba da palavra magazine [revista] com a sílaba inicial de fanatic).

Existem sites especializados em fanfic como www.fanfic.net e http://www.fanfiction.net; seu serviço é gratuito, e basta apenas que o internauta de qualquer parte do mundo faça um rápido cadastro e estará apto para postar seus contos. Esta, porém, não é a única forma de publicar fanfiction pela internet. Diversos outros sites, criados e mantidos por incentivadores do hobby, recebem trabalhos de outros escritores. Alguns o fazem de forma temática, como os diversos sites e blogs dedicados a fanfictions de Harry Potter, ou o site brasileiro Hyperfan (http://www.hyperfan.com.br), que só publica contos sobre personagens de quadrinhos das editoras norte-americanas Marvel e DC. O Hyperfan também se diferencia por sua política: eles contam com colaboradores fixos que escrevem regularmente sobre os mesmos super-heróis, em um universo paralelo onde os personagens das duas editoras, rivais entre si, coexistem normalmente.

Atualmente, é impossível contabilizar quantos são os sites dedicados à publicação de fanfics, já que centenas de jovens publicam suas histórias de forma descentralizada em blogs pessoais, páginas de grupos de amigos ou sites dedicados a 
"gêneros" ou universos ficcionais específicos. Um dos mais populares sites dedicados às fanfics, o FanFiction.net, possuía mais de 1,3 milhão de usuários cadastrados em outubro de 2007, dentre os quais muitos brasileiros, segundo dados do site, mas mesmo esse não pode ser utilizado como parâmetro único.

Os fanfics são organizados por tipos, classificados por público e faixa etária, conforme descrição apresentada abaixo:

\section{1 - Tipos de Fanfiction}

\section{a. Doujinshi}

Fanficção japonesa, baseada nos mangás, escritos e desenhados por fãs destas séries, como se fosse uma fanzine de um mangá. O termo deriva de Doujin ou grupo literário, que era a forma tradicional de produção, e Shi, que significa revista ou distribuição. Alguns podem considerar trabalhos de aficcionados (fanwork), para muitos são simplesmente publicações de mangá de pequena tiragem.

Normalmente, o termo usualmente se refere a mangás/fanzines de artistas não profissionalizados, podendo conter tanto histórias originais quanto baseadas em um mangá ou um anime da moda, bem popular. Entretanto, escritores de fanfics que se dedicam a criar histórias inspiradas em animes e mangás classificam seus trabalhos como doujinshi, mesmo quando é apenas texto e não possui ilustrações.

O termo Doujinshi Circle é utilizado para designar um grupo de artistas que trabalham juntos na criação de uma obra. A Clamp começou sua carreira como um Doujinshin Circle, contando com 11 integrantes no começo.

\section{b. Mary Sue}

Alguns tipos de fanficções são chamadas pelo estilo Mary Sue, um formato mais "açucarado" em forma de conto, romance ou novela, melodramática e apelativa. O nome do estilo é uma homenagem à Tenente Mary Sue, uma personagem de fanfics de Jornada das Estrelas dos anos 80 que definiu o arquétipo da personagem perfeita altamente idealizada.

Também são chamados Mary Sue (ou Gary Stu, na versão masculina) as fanfictions onde o personagem principal é praticamente onipresente, sendo completamente inatingível. 


\section{c. Outros Tipos}

Darkfic - Fanfic abundante em cenas depressivas, atmosferas sombrias e situações angustiantes. É o contrário das fanfics definidas pelo termo "waffy".

Deathfic - Onde os personagens principais morrem.

Slash - Fanfic cujo tema principal concentra-se na relação (amorosa, de amizade etc) entre dois personagens centrais. "Slash" é a palavra em inglês para "barra". Ex: Aragorn/Boromir, Spock/Kirk, Mulder/Scully. A grande maioria atualmente interpreta o termo como sinalização de relacionamentos homossexuais masculinos.

Femeslash - Fanfic com relacionamento homosexual feminino.

Fanon - Indica a presença de idéias já propagadas em outras fanfics e que se tornaram tão populares quanto a obra original.

Lemon - Fanfic com cenas de sexo entre homens (detalhada).

Orange - Fanfic com cenas de sexo entre mulheres (detalhada).

Yaoi - Fanfic com romance entre dois homens.

Yuri - Fanfic com romance entre duas mulheres.

Shonen-ai - Fanfic com romance entre dois homens (leve).

Shoujo-ai - Fanfic com romance entre duas mulheres (leve).

Shotacon - Fanfic com romance entre um homem mais velho com um mais novo.

Lolicon - Fanfic com romance entre uma mulher mais nova e uma mulher/homem mais velho(a) - O termo deriva da estória "Lolita".

Hentai - Fanfic com cenas de sexo (explicitamente).

Citrus - Fanfic de romance adulto, pode ou não conter cenas de sexo.

Canon - Segue o "Cânone". Refere-se a fanfics que sigam fielmente a história, principalmente em termos de shippers (casais) e caracterização de personagens.

Oneshot - Fanfic que contém somente um capítulo (one-shot: um-tiro (por ser uma leitura rápida), seja ele curto e postado de uma só vez, ou longo e postado em partes. 
Songfic - Quando a fanfic segue acompanhada da letra (e/ou tradução) da música, escolhida pela autora, como trilha sonora. Geralmente seu gênero é drama e são Oneshots.

U.A. (Universo Alternativo) - Quando a fanfic se passa num mundo diferente do criado pelo(a) autor(a) original da série, mas utilizando os personagens já existentes na história, na maioria das vezes buscando não alterar as características físicas e psicológicas das personagens.

\section{2 - Tipos de Classificação}

$G$ (Livre ou $K / K+)$ - Fic liberada para todas as idades. O site Fiction Ratings subdivide esta classificação em duas categorias: $\mathrm{K}$ e $\mathrm{K}+$.

K: Conteúdo livre de qualquer linguagem grosseira, violência e temas adultos.

$K+$ : Conteúdo com menor grau de violência, insinuações de linguagem grosseira e ausência de temas adultos, recomendável para crianças maiores de 9 anos.

PG-13 (NC-13 ou T): Não recomendável para menores de treze anos por conter alguma violência, linguagem levemente grosseira e sugestão de temas adultos. Cenas leves.

PG-15 (PG ou NC-15): Não recomendável para menores de quinze anos por conter cenas de violência, linguagem grosseira e temas adultos leves. Cenas estilo médio.

PG-17 (NC-17, M/MA ou R): Não recomendável para menores de dezessete anos por conter cenas de descrição explicita de violência, uso liberado de forte linguagem grosseira e temas adultos tratados de modo detalhado e explícito. Cenas fortes.

\section{O CIBERESPAÇO COMO “NÃO-LUGAR” DO FAZER LITERÁRIO}

O termo ciberespaço, desde seu uso pela primeira vez por William Gibson, tem atingido desdobramentos diversos de modo a se tornar um "lugar" da civilização moderna e de operação da humanidade, conforme Lévy (2000, p. 111), ampliando possibilidades na construção de um novo saber ou de um saber derivado, (re)construído como forma de questionamento da originalidade, do cânone e da autoria. Dessa forma 
desdobra saberes já constituídos, operando com pressupostos da Teoria e Crítica Literária e gera tensões, visto que a situação nessa busca não é pacífica, nem pode ser; pois, de um lado, constata-se que uma recusa obstinada em admitir a emergência de novos paradigmas literários, em nome de um purismo passadista, torna realmente difícil compreender como se pode refletir acerca das textualidades contemporâneas; de outro, nota-se o esforço de alguns teóricos para entender as lógicas que estão por trás dos hipertextos informatizados, procurando desvendar como eles estão criando novos elementos e em que medida se remetem às reflexões teóricas anteriores acerca do texto literário impresso. A tensão aqui apresentada, já é, há muito, presenciada em outros contextos, mais especificamente nas arenas da Abralic, quanto ao lugar da Literatura Comparada e dos Estudos Culturais, ou o lugar desse na Literatura Comparada. Tem-se notado isso com grande ênfase na defesa de um campo especificamente literário expresso no artigo de Leyla Perrone, cuja preocupação reflete uma busca da permanência do poder hegemônico do cânone constituído pela comunidade de letrados. Nota-se, dessa forma, que nesse discurso não há lugar para a literatura subalterna e marginal, sobretudo a produzida no ciberespaço, visto que nessa não há preocupação com as regras impostas pela "comunidade de letrados", é uma arte marginal que rompe com as imposições da arte hegemônica, aquela que decide pelo cânone, pela literaridade.

Em defesa dessa arte marginal no ciberespaço, Lima afirma que

Para uma compreensão mais aprofundada dessa literatura marginal (marginal aqui no sentido de estar à margem da mídia e do mercado editorial) é preciso que se tenha em mente o contexto de uma sociedade democrática (...), dentro dos moldes dos países capitalistas ocidentais, no ambiente das grandes cidades, na era da comunicação eletrônica e do domínio da mídia financiada pelas grandes empresas multinacionais. Em termos culturais, esse tipo de sociedade parece já reconhecer que existem divergências e não mais se concebe um padrão único de língua, tradições, lazer, religião e arte. Esta sociedade não vive sob a égide de um consenso estético, mas sob o delicado regime da convivência entre as diferenças, em que tensões e rivalidades são normais.

Assim, a literatura produzida nesse ambiente constitui-se uma forma de resistência, de tentativa de deslocamento do hegemônico, de enfrentamentos políticos, visto que questiona a autonomia autoral; constitui-se, portanto, numa literatura menor ${ }^{1}$ nos moldes deleuze-guatarrianos. 
Nesse sentido, Wander Miranda propõe que a Literatura Comparada deve ser tratada como um espaço de travessia, ao mesmo tempo limite e limiar da possibilidade de estudos que os estudos culturais acentuam nos estudos literários. Assim, pode-se notar que, quanto à literatura produzida no contexto do ciberespaço, como lugar de passagem, de travessia para os EC a literatura é enaltecida, visto que seu campo é alargado na forma e no conteúdo, novas formas de divulgação (apesar de questionado o eixo), de divulgação da obra que lhe serviu de "matéria-prima" assim como de propostas de conteúdos esquecidos pelo cânone.

Assim, o tipo de subjetividade que circula hoje depende, como bem sublinha Anthony Giddens, de conexões que os indivíduos estabelecem com os novos horizontes abertos, seja no âmbito da tecnociência, seja no âmbito sociopolítico, seja na inscrição urbana da alta-modernidade. As novas tendências apontam em diversas direções, acenando para um presenteísmo hedonista, para a competição desenfreada, bem como para o questionamento de valores que possam propiciar uma nova solidariedade.

Nesse contexto, observa-se que a literatura como uma cultura derivada, produzida no ciberespaço por fãs, como consequência da tecnociência da altamodernidade, ou a modernidade líquida, tão bem definida por Bauman (2002) derivada aqui não no sentido de fonte e influência proposto pelo comparativismo francês ${ }^{1}$, mas como desdobramentos culturais - apresenta-se como desdobramentos e não como mera cópia, pois a "idéia do original é criada pelas cópias e o original é sempre adiado para nunca ser surpreendido" (Culler, 1999, p.21).

\section{O LUGAR DA AUTORIA NA CULTURA DO FANFICTION}

A literatura produzida por fãs permite fazer ainda uma reflexão sobre o lugar e a noção de autoria. Segundo Michel Foucault (1992, p.32) "a noção de autor constitui-se num momento forte da individualização na história das idéias, dos conhecimentos, das literaturas, na história da filosofia também, e na das ciências". Foucault aponta o autor como um agrupamento do discurso, como unidade e origem de suas significações, como foco de sua coerência, de um discurso que seria sagrado, separando-o do discurso comum, funcional que produzimos diariamente. Desta forma, o nome autor assegura uma idéia classificatória, na qual o agrupamento e delimitação de determinados textos 
caracteriza certa forma de ser do discurso. Não se pode esquecer que, para ele, essa "função autor" vai servir para a circulação e o funcionamento de determinados discursos. É, nesse contexto que nasce a ideia de autoria, "na medida em que o autor se tornou passível de ser punido, isto é, na medida em que os discursos se tornaram transgressores", conforme Foucault (1992, p. 47).

Roland Barthes, por sua vez, ao analisar a literatura, diz que a imagem da literatura está tiranicamente centrada no autor. Barthes (2010 online) afirmou que o "texto é uma célula de citações montadas de inumeráveis centros de cultura"; ele questiona a visão do autor centralizado no indivíduo, dono do seu discurso.

O ciberespaço se constitui como um espaço de construção de autores anônimos, lugar de onde emergem novas discursividades; constitui-se, ainda, como um ambiente que se propõe a pensar os sentidos e os sujeitos em sua relação com a língua, a cultura e a história. A noção de autoria na (re)escrita hipertextual, na qual a ideia de completude e unidade, ainda que como efeito, parece se diluir no espaço constituído pelo ciberespaço, o sujeito-autor, enquanto enunciador, assume uma posição determinada (por condições sócio-ideológicas), revelando, a partir da unidade que tenta conferir ao seu texto, que é parte de um hipertexto, a sua própria unidade enquanto sujeito. Nessa perspectiva, a função-autor, ao (re)estruturar o discurso do outro, produz textualidade, ou seja, confere ao texto um efeito de unidade imaginário e cria também um efeito de transparência dos sentidos, dissimulando, desse modo, a dispersão e a incompletude constitutivas do sujeito e do discurso.

Nesse sentido, um escritor de fanfiction, um ficwrigth, na medida em que passa a escrever mais e mais histórias, trabalha com outras vozes, com um discurso multifacetado e demonstra não só habilidade na escrita, mas também conhecimento do seu universo cânone, visto que sabe distinguir os gêneros de fanfiction e os mais aceitos pelos leitores e pela fanzines e, dessa maneira, mantém contato com outras comunidades de fã (com outros discursos).

Assim, a noção de autoria nesse contexto é deslocada; para Marco ${ }^{1}$ essa noção passou a sofrer um deslocamento desde as vanguardas; ela afirma que com a pregação da "morte da arte", Duchamp decretava a morte do autor nos moldes modernistas, levantando conceitos simbólicos da antiarte e do antiartista. Esta apologia da morte da 
arte situava-se numa função de antídoto, sendo praticada pela arte Dadá, num discurso ambíguo de salvação - matar para salvar. Nesse sentido, torna-se necessário fazer referência, mais uma vez, ao conceito de Barthes (2010, online) quando, ao concluir seu texto sobre a morte do autor, usa a seguinte frase: "sabemos que, para devolver à escrita o seu devir, é preciso inverter o seu mito: o nascimento do leitor tem de pagar-se com a morte do Autor."

\section{CONSIDERAÇÕES FINAIS}

O mass entertainment contemporâneo adentrou pelos cômodos, tomou conta das práticas diárias e imbricou-se ao privado de tal modo que a vida passou a funcionar como uma obra de arte coletiva. As ações do cotidiano passaram a operar no contexto da cibercultura, e o ciberespaço passou a ser o lugar de operação da humanidade, suas produções, sobretudo as literárias, que foram (re)configuradas. O que era um diário comum passou a ser um blog, a poesia perde-se enquanto lugar da palavra e transformase em vídeo-poema (embora o vídeo poema não seja tão novo, pois já fora trabalhado em outros contextos, como na poesia concreta de Pignatari e os irmãos Campos) e, enfim; os conceitos que aprisionam tudo, agora precisam ser também repensados nesse novo contexto.

Diante disso, percebe-se que a velha questão "se blog é literatura", ou se o que é produzido nele pode ser considerado literatura, que há muito inquietava os críticos, hoje não é mais pertinente, mas uma nova questão deve nascer daí: qual a contribuição da internet para a literatura e que nova literatura tem surgido a partir da internet? E, ainda, como a internet serve de suporte aos novos autores? Quais as contribuições culturais desse novo contexto, sobretudo para a cultura marginal e subalterna?

É notável que os desdobramentos literários, a partir das contribuições do ciberespaço, sobretudo na cultura de fã, nas fanfics, ainda suscitarão muitos questionamentos e possíveis tensões entre LC e EC, sobretudo na defesa do lugar campo hegemônico da literatura e do cânone. Cabe aqui aproveitar as contribuições, também, dos Estudos Culturais e tratar a literatura como um lugar de travessia, como propõe Wander de Miranda, pois assim ela será, não o ponto de partida ou de chegada, com pretensões universalizantes, mas um lugar de convergência cultural, um entre-lugar 
de culturas e discursos, assim como o ciberespaço o é; não como o lugar da humanidade, mas como um local onde ela opera. Nesse sentido, cabe também refletir sobre a noção de autoria que os ficwriters trazem, como eles agem nas margens e seu posicionamento literário, não simplesmente como (re)escritores, divulgadores/disseminadores da cultura dominante, mas como, em sua posição de subalternidade, buscam alternativas, modificam e afetam a cultura dominante. É preciso notar ainda, que a pretensa defesa de um campo exclusivo é nada mais que a inquietação do "eixo", que teme perder seu referente, que teme ser movido, deslocado pelas/para as margens.

\section{REFERÊNCIAS}

BARBERO, Jesús Martín. Dos meios às mediações: comunicação, cultura e hegemonia. $4^{\text {a }}$ ed. Rio de Janeiro: UFRJ, 2006.

BARTHES, Roland. A morte do autor. Disponível em http://www.eulalia.kit.net/textos/barthes.pdf acesso em 21 de fev. de 2010.

BAUDRILARD, Jean. Cultura y simulacro. Tradução por Pedro Rovira. Barcelona: Kayrós, 1978. Documento em pdf, disponível em: http://www.4shared.com/file/54231107/c027eb28/Jean_Baudrillard_-

_Cultura_y_s.html?s=1, acessado em 22 de fevereiro de 2010.

BAUMAN, Zigmunt. Modernidade líquida. Rio de Janeiro, Jorge Zahar Editor, 2000.

CARVALHAL, Tânia Franco. Literatura comparada. São Paulo: Ática, 2006.

CULLER, Jonathan. Teoria literária: uma introdução. [Trad. Sandra Vasconcelos] São Paulo: Beca, 1999.

DELEUZE, Gilles \& GUATARRI, Félix. Kafka: por uma literatura menor. Trad. Rafael Godinho. Lisboa: Assírio \& Alvim, 2003.

FOUCAULT, Michel. O que é um autor. Lisboa: Passagens/Vega, 1992.

GIDDENS, Anthony. As conseqüências da modernidade. Rio de Janeiro: Jorge Zahar, 2002.

JOHNSON, Steven. Cultura da interface: como o computador transforma nossa forma de criar e comunicar. Rio de Janeiro; Jorge Zahar Ed., 2001. 
LÉVY, Pierre. A inteligência coletiva: Por uma antropologia do ciberespaço. $4^{\mathrm{a}}$ ed. São Paulo: Loyola, 2003.

. Cibercultura. $2^{\text {a }}$ ed. São Paulo: Editora 34, 2000.

. O que é virtual? $1^{\text {a }}$ ed. São Paulo: Editora 34, 1996.

LIMA, Luciano Rodrigues. O hipertexto literário na internet: apenas o poema em tela ou uma nova arte verbal cibernética? Disponível em, http://www.hipertextus.net/volume1/artigo10-luciano-lima.pdf, acessado em $15 \mathrm{de}$ dez. de 2009.

A guerrilha literária: a voz dos excluídos na internet. Disponível em: www2.docentes.uneb.br/.../GUERRILHA\%20LITERARIA.doc Acesso em 20 de fev. de 2010.

MAFFESOLI, Michel. Sobre o nomadismo, vagabundagens pós-modernas. Trad. de Marcos Castro. Rio de Janeiro: Record, 2001.

MARCO, Kátia de. A diluição do autor na cibearte. Disponível em http://www.gestaocultural.org.br/pdf/autornaciberarte-katia.pdf, acessado em 16 de dezembro de 2009.

MIRANDA, Fabiana Móes. Fanfic e fanfiqueiros: leitores/fãs de livros/escritores. In: HIPERTEXTO, 1., 2005, Recife. $1^{\circ}$ Encontro Nacional Sobre Hipertexto: desafios lingüísticos, literários e pedagógicos. Recife: UFPE, 2005. Disponível em http://www.ufpe.br/hipertexto2005/TRABALHOS/Fabiana\%20M\%F3es\%20Miranda.ht m. Acesso em: $10 \mathrm{fev} .2010$.

MIRANDA, Wander Melo. Projeções de um debate. Revista Brasileira de Literatura Comparada. Abralic, n 4. Florianópolis, 1998.

PERRONE-MOISÈS, Leyla. Que fim levou a Crítica Literária? Folha de S. Paulo, 25 de ago. de 1996.

SANTIAGO, Silviano. O Cosmopolitismo do pobre. Belo Horizonte: Editora UFMG, 2004.

RECEBIDO EM: 04 de maio de 2011

APROVADO EM: 08 de junho de 2011 